\title{
Theoretical modeling of Ring-Locked S-shaped acceptor molecules for High-Performance Organic Solar Cells
}

\author{
Malik Muhammad Asif Iqbal ${ }^{1}$, Muhammad Mehboob ${ }^{1}$, Dr. Riaz Hussain ${ }^{1}$, Talha Hassan ${ }^{1}$, \\ and Muhammad Ramzan Saeed Ashraf Janjua ${ }^{2}$ \\ ${ }^{1}$ University of Okara \\ ${ }^{2}$ King Fahd University of Petroleum and Minerals
}

December 8, 2021

\begin{abstract}
The introduction of a bridge element to covalently ring-lock the neighboring aryl or heteroaryl groups connected by a single bond has led to a variety of fascinating multifused ladder-type structures. Here, we have designed a new series of $2 \mathrm{H}-\mathrm{pyran}$ containing tetracyclic dithienocyclopentapyran compounds (MMA1 to MMA3). Long conjugation at end-capped of designed systems enhances the power conversion efficiencies of non-fullerene-containing organic solar cells. Different geometric parameters of designed systems have been examined through density functional theory and time-dependent density function theory. Designed molecules expressed high absorption maxima values with a reduced energy bandgap. Open circuit voltage along with transition density matrix analysis recommended that charge transfer occurs from lower energy orbitals to higher energy orbitals. Reorganization energy analysis also suggested high charge mobility occurs from donor polymer to acceptor molecules. Results of all parameters advocated that designed molecules are potential candidates for high-performance organic solar cells.
\end{abstract}

\section{Hosted file}

Manuscript.docx available at https://authorea.com/users/450230/articles/548590-theoreticalmodeling-of-ring-locked-s-shaped-acceptor-molecules-for-high-performance-organic-solarcells 